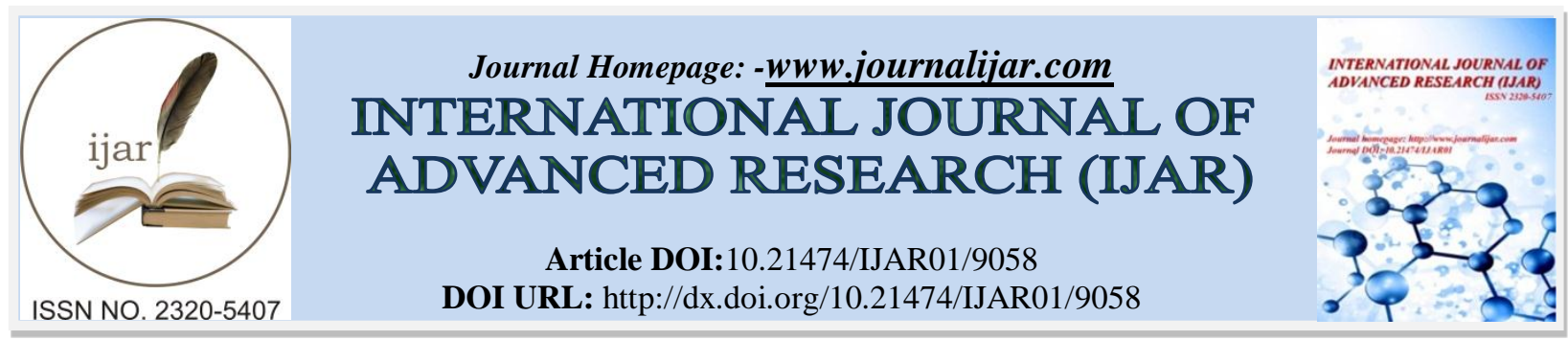

RESEARCH ARTICLE

\title{
A COMPARATIVE STUDY OF MANUAL VACUUM ASPIRATION AND DILATATION \& CURETTAGE FOR FIRST TRIMESTER TERMINATION OF PREGNANCY.
}

Dr. Kumkum Gupta ${ }^{1}$ And Dr. Bharti saxena ${ }^{2}$.

1. Assistant Professor Obstetrics \& Gynecology Government Medical College, Kota Rajasthan.

2. Senior Professor Obstetrics \& Gynecology Government Medical College, Kota Rajasthan.

\section{Manuscript Info}

Manuscript History

Received: 13 March 2019

Final Accepted: 15 April 2019

Published: May 2019

\section{Abstract}

Copy Right, IJAR, 2019,. All rights reserved.

\section{Introduction:-}

Traditionally first line management for pregnancy failure and MTP has been D\&C which requires trained personel,operating room,presence of anaesthetist and sometimes blood transfusion.

Despite careful and skilled intervention even in best hands complications like haemorrhage, incompleteevacuation,perforation and infection can occur.

MVA as means of removing uterine contents was pioneered in 1958 by Yuvantai and Xiamzhen in China .It ultimately lead to the technique becoming a common and safe obstetric procedure. MVA is safer and can be easily performed in OPD setting (hence cost effective) highly portable virtuallysilent,reusable and available at low cost. Despite numerous studies now available stressing the superiority of MVA over D\&C yet traditionally accepted D\&C is the final answer whenever there is doubtful completeness of procedure during MVA hence D\&C as a tool can not be forgotten \&should not be abandoned. When it is done by trained persons under standard conditions it is safe with negligible complications. Out of estimated 211 millions pregnancies that occur every year about 46 million end in induced abortions of which only $60 \%$ are carried out under safe conditionsMore than 18 million induced abortions each year are performed by people lacking necessory skills or enviroment lacking minimal standard or both.

\section{Aim}

To study the safety and efficacy of MVA in first trimester termination of pregnancy in comparisionto D\&C.

\section{Objective}

1. To compare safety and efficacy of the two methods of termination of pregnancy up to 12 weeks of gestation.

2. To compare time taken during the procedure, anaesthesia required, intraoperative blood loss, post operative blood loss and other complications.

3. To observe various complications like cervical injury, uterine perforation and incomplete procedure.

\section{Material and method:-}

This prospective randomized study was conducted in dept of obstetrics and gynecology,government medical college kota from dec 2015 to dec 2017,in women seeking first trimester MTP.200 cases of pregnancy seeking MTP due to 
different reasons were selected according to following criteria,allocated randomly to undergo MVA(100 cases group1)and D\&C(100 cases group2).

\section{Inclusion criteria:}

Women with pregnancy upto or less than 12 weeks of gestation were included in this study.

\section{Exclusion criteria:}

1. Gestational age more than 12 weeks as confirmed by usg.

2. Irregular uterine cavity.(large submucosalfibroid,septate or bicornuate uterus.

3. Bleeding disorders

4. Genital infections.

Detailed menstrual, obstetrical, medical and surgical history taken from women of both groups. Clinical examination was done to know the position,size and mobility of uterus,presence of infection and rule out ectopic pregnancy. The patients were subjected to routine investigations

After explaining the procedure and its advantages to the patient,an informed written consent was taken. . In all 200 cases,time taken for the procedure,intraopertive and post operatve blood loss and other complications were studied.

Time: time taken for the procedure was measured in minutes, from the insertion of cannula till the sign of complete evacuation of uterus.

Intraop blood loss: blood loss during the procedure measured in mililitre by noting the collection $\mathrm{n}$ MVA syringe and the material collected in kidney tray during D\&C. measurement of blood loss included the product of conception, decidual tissue and blood.

Postop blood loss: In post operative period,amount of bleeding was assessed by checking the soakage of diapers. Woman was monitored for anaesthesia complications like headache, nausea, vomiting and allergic drug reactions.and discharged accordingly with appropriate contraceptive method.

Table 1:-Age Wise Distribution of Cases

\begin{tabular}{|c|c|c|c|c|}
\hline Age in yrs & $\begin{array}{l}\text { MVA } \\
\text { N=100 }\end{array}$ & $\begin{array}{l}D \& C \\
N=100\end{array}$ & TOTAL & Percentage \\
\hline$<\mathbf{2 0}$ & 6 & 5 & 11 & $5.5 \%$ \\
\hline $21-25$ & 35 & 33 & 68 & $34 \%$ \\
\hline 26-30 & 40 & 44 & 84 & $42 \%$ \\
\hline 31-35 & 14 & 12 & 26 & $13 \%$ \\
\hline$>35$ & 5 & 6 & 11 & $5.5 \%$ \\
\hline Total & 100 & 100 & 200 & $100 \%$ \\
\hline
\end{tabular}

Table 2:-Gravida Wise distriburtion of Cases

\begin{tabular}{|l|l|l|l|l|}
\hline Gravida wise & $\begin{array}{l}\text { MVA } \\
\text { N=100 }\end{array}$ & $\begin{array}{l}\text { D\&C } \\
\text { N=100 }\end{array}$ & Total & Percentage \\
\hline unmarried & $\mathbf{0}$ & $\mathbf{0}$ & $\mathbf{0}$ & $\mathbf{0 \%}$ \\
\hline primigravida & 5 & $\mathbf{3}$ & $\mathbf{8}$ & $\mathbf{4 \%}$ \\
\hline $2^{\text {nd }}$ gravida & 28 & 19 & 47 & $\mathbf{2 3 . 5 \%}$ \\
\hline $3^{\text {rd }}$ gravida & 37 & 43 & $\mathbf{8 0}$ & $\mathbf{4 0 \%}$ \\
\hline $4^{\text {th }}$ gravida & 20 & $\mathbf{2 5}$ & $\mathbf{4 5}$ & $\mathbf{2 2 . 5 \%}$ \\
\hline$>4$ & 10 & 10 & $\mathbf{2 0}$ & $\mathbf{1 0 \%}$ \\
\hline total & 100 & 100 & $\mathbf{2 0 0}$ & $\mathbf{1 0 0 \%}$ \\
\hline
\end{tabular}

Table 3:-Gestational Age Wise distribution of Cases

\begin{tabular}{|l|l|l|l|l|}
\hline $\begin{array}{l}\text { Gestational age } \\
\text { (weeks) }\end{array}$ & $\begin{array}{l}\text { MVA } \\
\mathrm{N}=100\end{array}$ & $\begin{array}{l}\mathrm{D} \& \mathrm{C} \\
\mathrm{N}=100\end{array}$ & Total & Percentage \\
\hline$<6$ & 12 & 9 & 21 & $10.5 \%$ \\
\hline $6-8$ & 52 & 53 & 105 & $52.5 \%$ \\
\hline
\end{tabular}




\begin{tabular}{|l|l|l|l|l|}
\hline $8-10$ & 25 & 24 & 49 & $24.5 \%$ \\
\hline $10-12$ & 11 & 14 & 25 & $12.5 \%$ \\
\hline Total & 100 & 100 & 200 & $100 \%$ \\
\hline
\end{tabular}

Table 4:-Amount of Blood Loss

\begin{tabular}{|c|c|c|}
\hline Blood loss $(\mathrm{ml})$ & $\begin{array}{l}\text { MVA } \\
\mathbf{N}=100\end{array}$ & $\begin{array}{l}\text { D\&C } \\
N=100\end{array}$ \\
\hline$<25$ & 4 & 0 \\
\hline $25-50$ & 67 & 8 \\
\hline $50-75$ & 26 & 30 \\
\hline $75-100$ & 3 & 34 \\
\hline$>100$ & $\mathbf{0}$ & 28 \\
\hline Total & 100 & 100 \\
\hline
\end{tabular}

Table 5:-Duration of Procedure

\begin{tabular}{|l|l|l|l|l|}
\hline $\begin{array}{l}\text { Duration } \\
\text { (minute) }\end{array}$ & $\begin{array}{l}\text { MVA } \\
\text { N=100 }\end{array}$ & $\begin{array}{l}\text { D\&C } \\
\text { N=100 }\end{array}$ & Total & Percentage \\
\hline$<5$ & $\mathbf{5 8}$ & $\mathbf{1 2}$ & $\mathbf{7 0}$ & 35 \\
\hline $\mathbf{5 - 1 0}$ & $\mathbf{4 2}$ & $\mathbf{2 0}$ & $\mathbf{6 2}$ & $\mathbf{3 1}$ \\
\hline $10-15$ & $\mathbf{0}$ & $\mathbf{3 0}$ & $\mathbf{3 0}$ & $\mathbf{1 5}$ \\
\hline$>15$ & $\mathbf{0}$ & $\mathbf{3 8}$ & $\mathbf{3 8}$ & $\mathbf{1 9}$ \\
\hline Total & $\mathbf{1 0 0}$ & $\mathbf{1 0 0}$ & $\mathbf{2 0 0}$ & $\mathbf{1 0 0}$ \\
\hline
\end{tabular}

Table 6:-Complication of the Procedure

\begin{tabular}{|l|l|l|l|l|}
\hline Complications & $\begin{array}{l}\text { MVA } \\
\text { N=100 }\end{array}$ & $\begin{array}{l}\text { D\&C } \\
\text { N=100 }\end{array}$ & Total & Percentage \\
\hline $\begin{array}{l}\text { Anaesthetic } \\
\text { complication }\end{array}$ & 0 & 0 & 0 & 0 \\
\hline Cervical injury & 0 & 3 & 3 & 1.5 \\
\hline Uterine perforation & 0 & 1 & 28 & 0.5 \\
\hline $\begin{array}{l}\text { Excessive blood } \\
\text { loss(>100ml) }\end{array}$ & 0 & 28 & 0 & 14 \\
\hline $\begin{array}{l}\text { Incomplete } \\
\text { evacuation }\end{array}$ & 0 & 0 & 0 & 0 \\
\hline
\end{tabular}

\section{Results:-}

Present study included 200 cases undergoing MTP (upto 12 weeks) of which 100 cases was done by MVA and 100 cases was done by D\&C.

1. $05.5 \%$ cases were less than $20 \mathrm{y}, 5.5 \%$ cases were $>35$ year.majority of cases (42\%) were in age group $26-30$ years.and $13 \%$ cases were 31-35 y of age. Cases in both study groups was comparable.no significant difference found between these 2 groups. $P$ value $>0.05$ insignificant.

2. There was no unmarried girl in study group. $4 \%$ were primigravida, $23.5 \%$ second gravida,maximum cases were gravida three.(40\%),22.5\% were gravidafour,and $10 \%$ were gravida 5.no statistically significant difference was found between two groups $\quad \mathrm{p}$ value $>0.05$.

3. $10.5 \%$ cases were <6 weeks max cases $52.5 \%$ were between $6-8$ weeks, $24.5 \%$ had 8-10 weeks, $12.5 \%$ had 10 12 week gestational age . no statistically significant difference was found on comparision.

4. Mean blood loss was 50.65+_ 15.69(SD) in MVA group while in D\&Cgroup mean blood loss was 84.55+_ $24.006(\mathrm{SD}) . \mathrm{P}$ value $<0.00001$ (significant)

5. mean duration of procedure was $6.51 \mathrm{~min}$ for MVA group,whereas it was $16.33 \mathrm{~min}$ for $\mathrm{D} \& \mathrm{C}$ group,the difference between two group was statistically significant. (p value $<0.0001$ ).

6. The common complication was execessive blood loss $(>100 \mathrm{ml})$. which occurred in 28 cases of D\&C .while not a single cases of MVA had excessive blood loss. 
Cervical injury occurred in 3 cases of D\&C while not a single case of MVA.In most cases cause of cervical injury was excessive traction given to vulsellum to dilate the cervix with hegar'sdilator.the most dreaded complication which occurred in D\&C was uterine perforation.

Conclusion here was that both procedure resulted in complete evacuation while MVA had no complication D\&C had cervical injury in $3 \%$,excessive blood loss $(>100 \mathrm{ml})$ in $28 \%$ and perforation in $1 \%$.

\section{Discussion:-}

Comparision between two study groups(100 cases of MVA and 100 cases of D\&C) has been done on following criteria.

1. timetaken for procedure

2. intraoperative blood loss

3. complications encountered

4. need for repeat evacuation

\section{time taken for procedure}

In present study we found statistically difference between two study groups on comparing the time taken for

\section{procedure}

MVA group D\&C group

6.51min+_1.997(SD) $\quad 16.33$ min+_8.267(SD)

$P$ value $<0.0001$ significant

Farooq f. Pakistan 2011 found statistically significant difference between MVA group(5.88 min+_2.43) as compared to D\&C group ( 8.98 min+_2.64) $\mathrm{p}$ value $<0.0001)$ with MVA taking statistically significant less time as compared to D\&C.which is similar to our finding.

Sheriar N et al 2007 studied use of MVA in first trimester MTP in a multicenter study in 27 clinics and quoted the time taken for procedure(MTP) as less than 5 min for $50.3 \%$ cases of less than 8 weeks and $26.1 \%$ cases of more than 8 week. $5-15$ min for $48.6 \%$ of $<8$ week and $66.3 \%$ of $>8$ weeks.more than 15 min for $1 \%$ of less than 8 weeks and $7.6 \%$ cases of $>8$ weeks.

Time taken for procedure correlate well with our study.difference in time taken between two studies is due to preoperative use of cervical ripening agent.

\section{Intraoperative blood loss}

1. Our study found statistically significant difference in the amount of blood loss during the procedure.

2. Khanni B et al 2010 found more blood loss in curettage group when compared to MVA group.

3. Faichamnan $\mathrm{S}$ et al 2010 reported lesser mean blood loss in MVA group.74.3ml+_60.1(SD) as compared to $104.2 \mathrm{ml}+$ 104.1(SD) in D\&C group which shows significantly difference (p value0.004)

4. These studies are having similar results as our study.

\section{Complications encountered:}

1. In our study there were no complication in MVA group,however in D\&C group there was cervical injury in 3\%, excessive blood loss in $28 \%$ and uterine perforation in $1 \%$

2. Faichamnan s.et al 2010 studied 67 patients of MVA and 67 patients of D\&C done for incomplete abortion and found 2 patients had incomplete evacuation in MVA group and 4 patients in D\&C group developed pelvic infection.there was no report of maternal death,uterine perforation and cervical injury.

3. Overall complication rate for MVA $2.98 \%$ and D\&C 5.97\%.not statistically significant difference for frequency of complete abotion and complication.

4. Pereira $\mathrm{P}$ et al2006 found no complication in 50 patients of MVA group and 50 patients of D\&C group.

5. Choobun $\mathrm{T}$ et al 2012 studied 40 cases of incomplete/missed/blighted ovum with MVA or sharp curettage and found no complication needing further curettage or other treatment in either group.

6. Thus the complications encountered during the procedure in our study correlate with all other studies mentioned above. 


\section{Need for repeat evacuation :}

In our study there was no case of incomplete evacuation in either of the group which shows both the procedure to be highly effective.

Faichamnan S.2010 in a study of MVA and D \&C women with incomplete abortion found incomplete evacuation in 2 cases out of 67 cases of MVA group.which required repeat evacuation while none of 67 cases of D\&C had incomplete evacuation.

Thus for D\&C group success rate is even higher(100\%) than MVA group (97\% ) but not statistically significant. Result of this study is different from ours as D\&C has been shown to be more efficient than MVA.

Choobun $\mathrm{T}$ et al 2012 quoted no cases of incomplete evacuation in either of 40 cases of $\mathrm{D} \& \mathrm{C}$ thereby providing the efficacy of both procedure.

This study have similar outcome as our study.

\section{Conclusion:-}

1. MVA can be easily and safely performed under paracervicalblock,thus avoiding comlpication related to regional and general anaesthesia.

2. the plastic cannula of MVA serves the purpose of cervical dilator,obviating the need of traumatic metallic dilator.

3. MVA requires less maintenance andhas easy method ofdisinfection as compared to D\&C decreasing the medical personnel and financial resource utilization.

4. the complication rate, duration of procedure,bloodloss, postop pain and bleeding was significantly less in MVA than in D\&C.

As MVA has many advantage and can be used as office procedure it is best suited for rural setting where there is an unmet need for abortion services.

D\&C has also shown to have equal success rates but slightly more complications.although D\&C requires sedation or GA and slightly more complication still it should not be forgotten,because in some conditions like open os and RPOC, where cannula does not fit snugly and vacuum leaks, when tip of cannula breaks accidently or at times pieces of membranes clog the cannula,rest of evacuation have to be done with D\&C.so the clinician has to make decision as to which method has to be used for individual patient with different characteristics to achieve a complete abortion with least possible complication, the clinician has to make decision as to which method has to be used for individual patient with different characteristics to achieve a complete abortion with least possible complication.

\section{Refrences:-}

1. Choobun T,khanuengkitkongS, pinjaroen S.A comparative study of cost of care and duration of management for first trimester abortion with MVA and sharp curettage.Archgynecol obstet.2012 nov;286(5)1161-4.

2. Farihafarooq,lubnajaved,amreenmumtaz,nosheennaved,comparision of MVA and D\&C in the treatment of early pregnancy failure.Jayub medical college abbottabad.2011;23(3).

3. Boonyarangkul,orawan-comparision of level of pain between using manual vaccume aspiration and sharp curettage in management of abnormal uterine bleeding.journal of medical association of thailand12/2011;94supp17;s57-61.

4. Millegos D,mathurM,SmithN,AshokP.manualvaccum a safe alternative for surgical management of early pregnancy loss.Br j obstet gnecol.2009;116:1268-71.

5. KamelH,GoswamiS,DuttaR.Manualvaccum aspiration and electrical vaccumaspiration;a comparative study MTP.J obstet gynecol2011;61:53-6

6. Tasneem N, Mahmud G, Fatima S, Sultana M. Manual vacuum aspiration; a safe and cost effective substitute of electric vaccum aspiration for surgical management of early pregnancy loss. J pak med assos 2011:149-53.

7. Ahsan A,Jafary SN.Unsafe abortion:Global picture and situation in Pakistan.J Pak Med Assoc.2008;58:660-1.

8. Das CM, Srichand P, Khursheed F, Shaikh F. Assessment of efficacy and safety of MVA(Manual Vacuum Aspiration). J Liaquat Uni Med Health Sci.2010'9:130-3.

9. Farooq F, Javed L, Mumtaz A, Naveed N. Comparison of manual vacuum aspiration, and dilatation and curettage in the treatment of early pregnancy failure. J Ayub Med Coll Abbottabad. 2011;23:28-31. 
10. Wen J, Cai Q, Deng F. Manual Vacuum aspiration for first trimester abortion; a systemic review. Br J Obstet Gynacol.2008;115:2-13.

11. Dao B, Blum J, Theiba B, Raghavan S. Is misoprostol a safe, effective and acceptable alternative to manual vacuum aspiration for postabortion care? Results from a randomized trial in Burkina Faso, West Africa. BJOG 2007;114:1368-75. 